\title{
Personnel resistibility in lean manufacturing
}

\author{
Elena Ganebnykh ${ }^{1, *}$, Olga Lezhnina $^{2}$, and Tatyana Zhilkina ${ }^{3}$ \\ ${ }^{1}$ Vyatka State University, Moskovskaya str., 36, Kirov, 610000, Russia \\ ${ }^{2}$ Vyatka State Agricultural Academy, October Avenue, 133, Kirov, 610017, Russia \\ ${ }^{3}$ Moscow State University of Civil Engineering, 26 Yaroslavskoye Shosse, Moscow, 109377, Russia
}

\begin{abstract}
One of the barriers of the lean manufacturing introduction in enterprises is staff resistibility to change. The article describes the impact of philosophy and the concept of lean manufacturing training on the level of staff readiness for change. The research object is an engineering enterprise. Using the ROC technique, the authors conduct observations before and after training. The analysis shows that the number of neutral and positively inclined personnel increased from $70 \%$ to $82 \%$ after the training. Global practice indicates that it is possible to state the absence of barriers to implementation when the threshold is $80 \%$ according to these indicators.
\end{abstract}

\section{Introduction}

The National Project "Labor Productivity and Employment Support" designed for 5 years has been implemented in Russia since 2009. The aim of the project is to increase labor productivity at least by $5 \%$ per year in medium and large enterprises of the basic nonresource sectors of the economy. The task of the project is to stimulate the introduction of advanced managerial, organizational and technological solutions to increase labor productivity and modernize fixed assets, including the use of tax preferences [1]. One of the most important tools for the implementation of the project is the introduction of lean manufacturing in the participating enterprises.

The lean manufacturing concept means involving all employees of a company. A common misconception is the belief that lean manufacturing aims to optimize production chains. The philosophy of this concept is based primarily on organizational changes. Lean Consult experts identify four main problems while implementing lean manufacturing:

1) The content area includes problems associated with an insufficient level of knowledge of lean manufacturing tools and technologies and with the lack of ideas how to improve processes;

2) The organizational area includes problems of lean manufacturing introduction, arising from weak or incorrect organization of the work to improve efficiency;

3) The internal political field associated with the staff resistibility to the introduction of any changes in general;

4) The value area includes the compliance of moral values accepted in the company with the values of the concept and philosophy of lean manufacturing.

*Corresponding author: ganebnykh@mail.ru 
Thus, almost all problems include the personnel factor, whose behavioral characteristics are associated with a willingness to change.

M. Hammer and J. Champy indicate that more than $70 \%$ of initiatives to introduce changes in organizations fail because of the insufficient focus of initiators on business processes, ignoring employees' values and beliefs, characteristics of the organizational culture, unsuccessful attempts to stimulate changes at places, poor competence of leaders, high resistance of workers, inaccurate assessment of a temporary resource (early stop of processes or their delay), etc. [2].

M. Smyth [3] has analyzed the success of implementing various types of changes and concluded that the most difficult changes to implement are changes related to organizational culture (Figure 1).

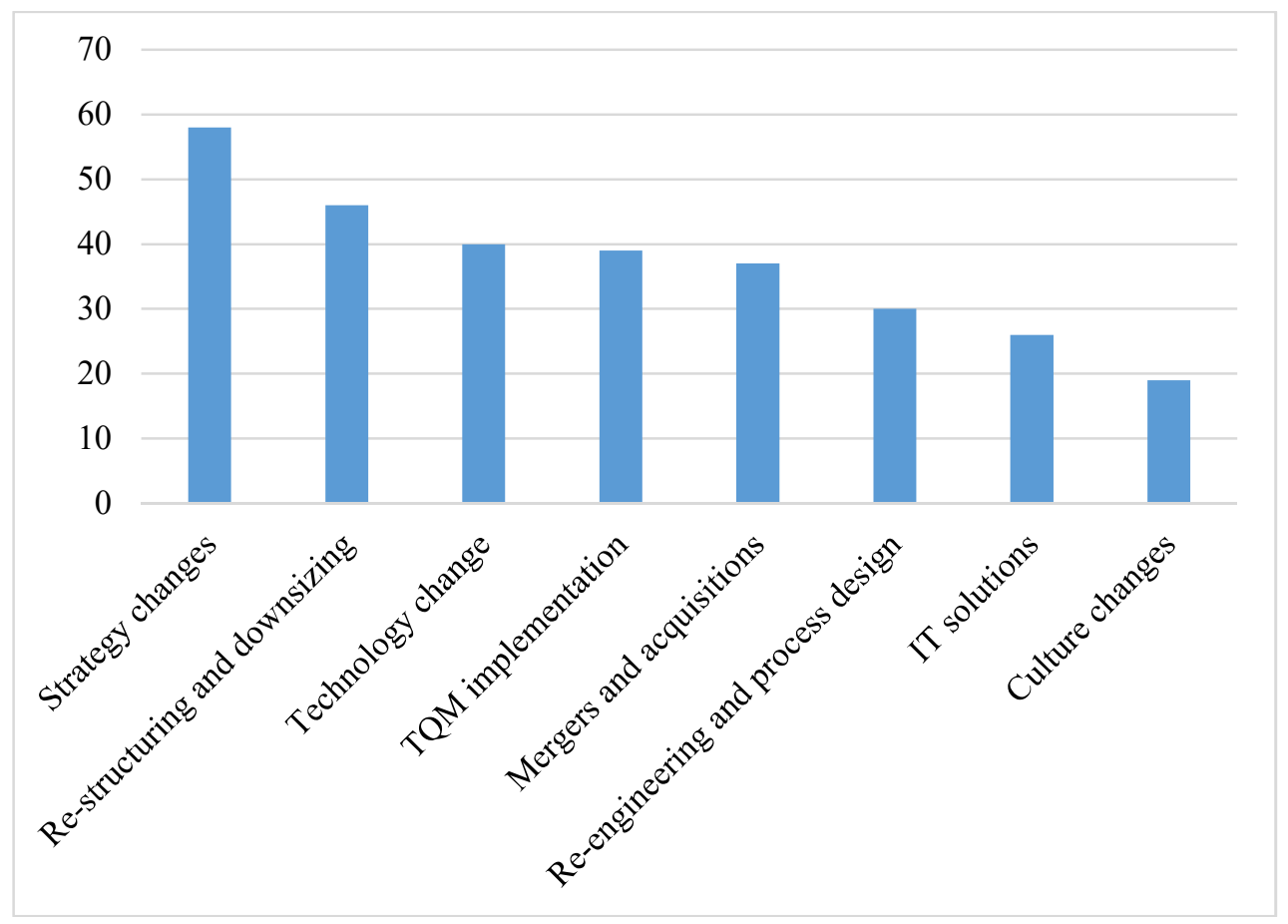

Fig. 1. Average success rating, $\%$.

It is well known that people do not like changes and are extremely wary of them. Psychological readiness of personnel for changes is widely discussed in modern literature. However, at the moment, researchers have not developed a common understanding of this psychological readiness. Modern theory distinguishes three relatively independent approaches.

D. Bouckenooghe in his review [4] highlights the attitude toward change approach, which considers psychological readiness as an attitude towards change. This approach identifies seven basic states of readiness: readiness for change, resistance to change, cynicism about organizational change, commitment to change, openness to change, acceptance of change and coping with change.

J. Prochaska, C. DiClemente, and J. Norcross have developed the integrative, biopsychosocial model to conceptualize the process of intentional behavior change [5]. Here change is considered as a dynamic process, where you can get a forecast of employee behavior at each stage, and readiness for change is one of the stages. The model offers five stages: precontemplation, contemplation, preparation, action и maintenance. 
I. Ajzen in his theory of planned behaviour connects behavior with belief [6]. According to this theory, attitudes, subjective norms, and perceived behavioral control form behavioral intentions and individual behavior. The factor of behavioral control is of interest here as it reflects a person's expectation of difficulties or relief after an action.

The Russian school of research on organizational behavior considers that a person is predisposed to changes and innovation, and this predisposition has a multi-level hierarchical structure [7]. In accordance with the strength of the innovative disposition, there are following types of attitudes to change: conservatives, moderate and innovators.

Obviously, the existing approaches to the analysis of the psychological readiness of staff for changes show that it has structural components (they are different depending on the approach) and can change over time.

\section{Methods and materials}

E.A. Naumtseva in her research describes and analyzes the main methods for assessing staff readiness for changes [8]. The main one is methodology Readiness for Organizational Change (ROC) developed by D. Holt and A. Armenakis [9].

The ROC methodology is the most cited and used in modern research methods for assessing readiness for organizational changes at the individual level. Authors consider willingness to change as a multimodal construct that is influenced by employees' beliefs that:

1) they are able to realize this change - effectiveness in the field of change (changespecific efficiency);

2) the proposed change is suitable for the organization - organizational valence;

3) leaders are committed to the proposed change - management support;

4) the proposed change is useful for members of the organization - personal valence.

The methodology has passed a psychometric test and has a high methodological rating according to The National Collaborating Centre for Methods and Tools (NCCMT).

As it was already mentioned above, one of the most important tools for the implementation of the national project "Labor Productivity and Employment Support" is the introduction of lean manufacturing at enterprises. Anticipating the barriers to implementation, individual participants are launching pilot projects, starting a year earlier than the federal program. The purpose of the pilot project is to identify the main problems, try to reduce the barriers to implementation, assess potential for reaching the target indicators.

One of such enterprises is the engineering company JSC Avitech, the city of Kirov. By the decision of the enterprise, there has been mass training of personnel on the basics of lean manufacturing during 2018-2020. The staff is explained the general philosophy and concept of lean manufacturing and is undergoing psychological preparation for implementing changes.

The hypothesis of the research is the provision that such initial introductory training reduces the staff's resistibility to changes. For this, we had to observe the presence of such changes before and after training.

Using the ROC methodology, we evaluated the readiness of the enterprise staff for changes before the training. 1986 respondents took part in it. Then, during the training, we monitored the personnel behavior, and according to it we distinguished 8 categories (Table 1). After training, we carried out a re-analysis of the control group of 98 people $(5 \%$ of the initial sample, a representative sample).

The training was carried out in groups of 16-24 people, while the groups were completed according to the principle of functional relationship (drivers, maintenance personnel, repair personnel) or in line units (workshop, department or working group). 
Table 1. Categories.

\begin{tabular}{|c|c|c|}
\hline Code & Category & Signs \\
\hline A1 & \multirow{2}{*}{$\begin{array}{l}\text { Conditional } \\
\text { neutrals }\end{array}$} & $\begin{array}{l}\text { "Executives" - they sit, look in the eyes, but it's difficult to track their } \\
\text { reaction, they write when they are asked to do it, they don't ask } \\
\text { questions, they don't comment on anything }\end{array}$ \\
\hline A2 & & $\begin{array}{l}\text { "Active neutrals" - they ask questions, give examples, but do not express } \\
\text { an opinion }\end{array}$ \\
\hline B1 & \multirow{2}{*}{$\begin{array}{l}\text { Conditional } \\
\text { Improvement } \\
\text { Leaders }\end{array}$} & $\begin{array}{l}\text { "Positives" - they nod their heads, agree that this is right, they doubt that } \\
\text { "it will work", but they don't resist changes, and if necessary they can } \\
\text { actively get involved in work }\end{array}$ \\
\hline B2 & & $\begin{array}{l}\text { "Enthusiasts" - they actively express their position, express options for } \\
\text { improvement, do not despair if they fail, are not afraid to try }\end{array}$ \\
\hline $\mathrm{C} 1$ & \multirow{2}{*}{$\begin{array}{l}\text { Conditional } \\
\text { Saboteurs }\end{array}$} & $\begin{array}{l}\text { "Smart men" - they know everything, are convinced of their rightness, } \\
\text { their expression is incredulous, arrogant, they think that they are wasting } \\
\text { their time in vain, but may not speak out loud }\end{array}$ \\
\hline $\mathrm{C} 2$ & & $\begin{array}{l}\text { "Saboteurs" - they are "against" the changes, speak out a lot and often, } \\
\text { but not always "on the topic", they don't listen to anyone, interrupt, can } \\
\text { use foul language, "shut up" their colleagues, put pressure on their } \\
\text { opinions }\end{array}$ \\
\hline D1 & \multirow[t]{2}{*}{ Uninterested } & $\begin{array}{l}\text { "Mice" - they look somewhere else (usually through the window), hover } \\
\text { in the clouds, are not interested in the topic, but do not interfere with } \\
\text { others }\end{array}$ \\
\hline D2 & & $\begin{array}{l}\text { "Sleepers" - they prop up the chin with their hands, look absent, may } \\
\text { periodically fall asleep }\end{array}$ \\
\hline
\end{tabular}

\section{Results}

Figure 2 and Table 2 shows the general primary staff division into categories. Initial observations showed that almost half of all employees (45\%) belong to group A (Conditional neutrals), while $3 / 4$ of all participants in this group can be attributed to category A1 (Executives). In general, this indicator is quite high, since the participants did not show hostility or biased negative attitude towards changes at the stage "before the introduction of changes". Accordingly, any measures designed to reduce barriers to overcoming resistance have all the prerequisites for improving the situation and transferring this category to Active Neutrals or even Positives.

Table 2. Results of initial observation.

\begin{tabular}{ccc}
\hline Cat & \% & Qty \\
\hline A1 & 32 & 887 \\
A2 & 13 & 265 \\
B1 & 15 & 296 \\
B2 & 10 & 204 \\
C1 & 5 & 64 \\
C2 & 3 & 51 \\
D1 & 19 & 192 \\
D2 & 3 & 27 \\
\hline$\sum$ & 100 & 1986 \\
\hline
\end{tabular}




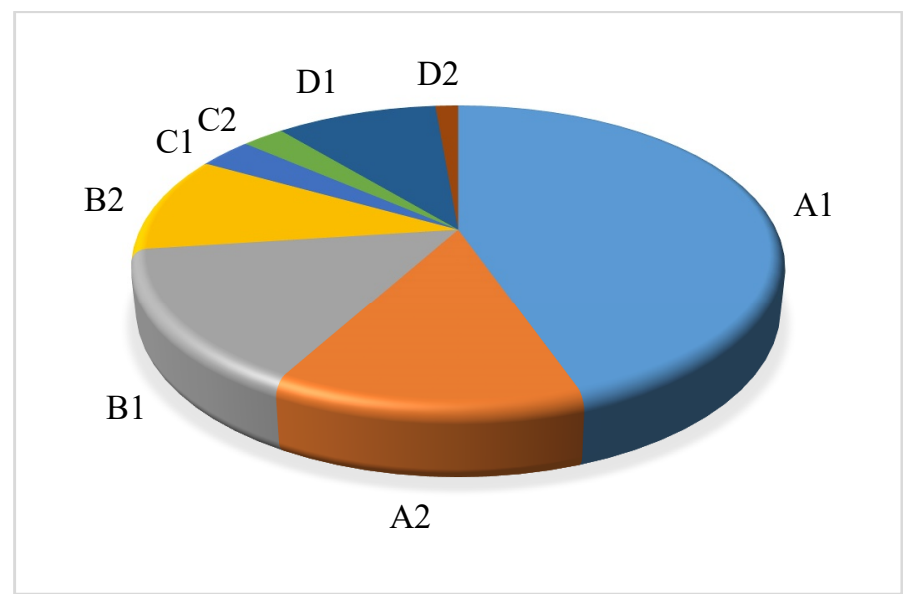

Fig. 2. The primary staff division into categories.

Contrary to the strong belief that about $20 \%$ of all personnel are usually classified as "saboteurs" [10], the study revealed only 3\% of pronounced "saboteurs" and another $5 \%$ of negative "smart men". In general, the category of "smart men" is not always negatively tuned precisely to future changes. Rather, their negativity is directed at the training procedure itself, since these people believe that they already know the subject of study and are wasting their time, which is certainly annoying.

A pleasant fact was the identified number of "Conditional improvement leaders" $(25 \%$ in total). The division of this category into groups of "Enthusiasts" and "Positives" is very similar to the theory of J. Bruhn, where he divides the leaders of improvements into change leaders and change managers [11]. This classification is valid for line units, since formal leaders and performers are present at the same time in such groups. However, this classification is not suitable for functional groups as a change manager role cannot be delegated to such listeners due to the specifics of their activities. Moreover, the size of the group itself, which actually determines a quarter of all participants, is very high.

Relatively small was the group of conditional passives (group D - "Uninterested"), it was $22 \%$ of all students. The category D1 is of interest here as it is potentially capable of moving into the group of "conditional neutrals". Obviously, during the training, such students need to be involved in the discussion and the work of groups, that is, you have to interest them. We can't give an unambiguous assessment to Group D2 as the cause of their drowsiness may be a simple malaise or problems of a personal nature that do not allow to focus on training. This group does not have negative behavior; therefore, it needs revaluation at another time.

After conducting an introductory training in philosophy and the concept of lean manufacturing, during which the task was to clarify the benefits of implementing this approach, to identify and reduce fears of upcoming changes, a control group was reevaluated to understand the changes in participants' behavioral reactions and the role training in reducing staff resistance to change.

The control sample included 2 groups formed by a functional basis, and 3 groups formed by linear subdivisions. An analysis of the reactions of 98 people showed changes in the structure of the personnel regarding readiness for changes (Figure 3, Table 3). 
Table 3. Results of control observation.

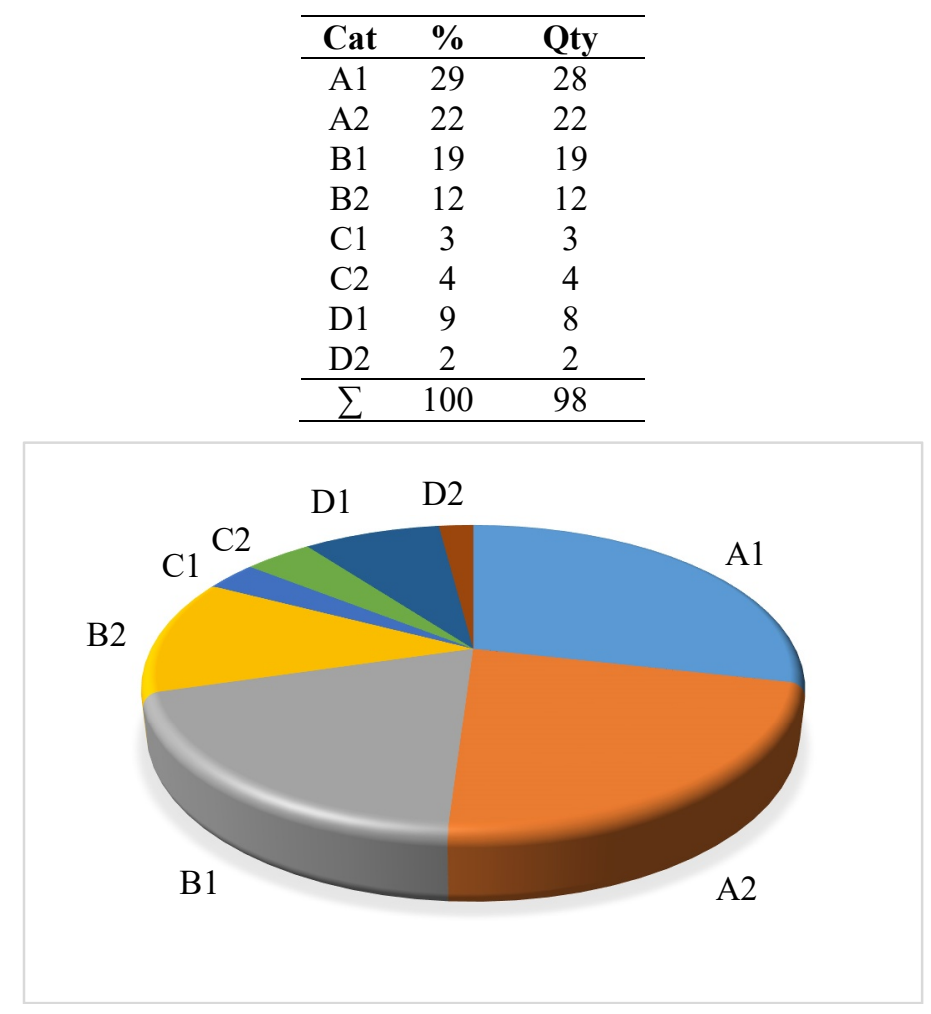

Fig. 3. The staff division into categories after the training.

Analysis of the changes showed that group $\mathrm{C}$ practically did not change. But the main donor for group A was group D, the size of which was halved - from $22 \%$ to $11 \%$. At the same time, group D1 ("Mice") came exclusively in category A1 ("Executives"). The main changes happened in groups A and B. The most important from the point of view of readiness for changes and the ability to introduce lean production at the enterprise group $\mathrm{B}$ increased from $25 \%$ to $31 \%$, and both subcategories increased. Group A also underwent significant changes. The size of the group increased from $45 \%$ to $51 \%$, the structural composition also changed: participants moved to more "active" categories: part of the participants moved to group B, and part moved from "Executives" to "Active neutrals".

Considering the fact that during changes it is usually possible to rely on groups B and A as leaders and followers during the transformations, it can be concluded that the training brings good results: the total volume of the group has increased from $70 \%$ to $82 \%$.

\section{Discussion}

The essence of lean manufacturing is primarily to change the way of thinking and behavior of employees. Moreover, the main postulate of the concept is the need for continuous improvement, that is, long-term changes without time limits. Personnel resistibility is an integral component of any qualitative transformation in the organization. The larger the transformation is planned, the more interests of more workers will be affected [12].

Following Lewin's Change Management Model, which refers to the three-stage process of change 'Unfreeze - Change - Refreeze' [13], active efforts to reduce the resistance of the organization's personnel are best done at the initial stage. In this case, the 
transformation of values and norms of activity during the course of changes occurs more smoothly. K. Lewin believed that training should be done in 2 stages: separately for potential improvement leaders (at the Unfreeze stage) and separately for the passive majority of employees (at the Change stage). However, in our study groups A and B relate to the active or potentially active part of employees. According to the results, these groups tend to grow by almost one and a half times with low costs for primary introductory education.

Probably, the difference in understanding the semantic load of learning leads to a different interpretation of the model. In fact, the primary training offered by the authors to reduce staff resistibility is introductory and educational. The course of this training doesn't consider lean manufacturing methods and tools, it only discusses a general philosophy and concept, approaches to understanding and managing processes, and presents successful practices.

Obviously, during such training, the main target group is category A, as they potentially have a good chance to move into the category of "conditional improvement leaders". The authors also recommend to pay special attention to the Group D as their behavior is not negative, which means there are chances to transfer them, at least, into the category of "conditional neutrals".

The need to work with group $\mathrm{C}$ involves a qualitative analysis of its composition. It is sad if formal leaders - heads of departments - are in this group. This means that most of the initiatives of groups A and B will not be implemented due to the resistance or inertia of the leadership. In the worst case, the behavior of the leader can provoke a decline in readiness for changes in the structural unit or personnel changes.

In general, if the group $\mathrm{C}$ has operational employees or service personnel who do not have decisive positions during the proposed changes, and the number of "saboteurs" D2 does not exceed $2-3 \%$ of the total number of participants, it makes no sense to spend a resource on changing the behavior of this group. In fact, this staff creates a healthy opposition and makes it possible to more closely assess the planned changes. Project management as a whole is quite positive about the role of skeptics and critics in the planning and implementation of projects [14]: Constructive criticism is valuable.

\section{Conclusion}

A study of the influence of staff training at the stage of preparing an organization for the implementation of lean manufacturing has shown its effectiveness. The number of potential improvement leaders increased by almost a quarter, while the enlarged group of conditional neutrals and improvement leaders increased by more than $17 \%$. In general, the number of employees who are positive or neutral in relation to the proposed changes reached $82 \%$ after training on the general philosophy and concept of lean manufacturing. Global practice indicates that when the threshold is $80 \%$, it is possible to predict the absence of barriers to implementation.

This research is a case-study as quantitative data describe the situation in a particular enterprise and cannot be generalized to other enterprises. The authors suggest that the general tendency towards the enlargement of groups A and B in enterprises of any industry will give a similar result in the initial introductory training. It is necessary to observe more objects in order to verify and confirm the hypothesis.

During the study we observed a readiness for changes related precisely to the introduction of lean production at the enterprise. In general, this approach is quite loyal to employees and is designed to make staff work more comfortable and safer. This fact is important in terms of reducing personnel resistibility as many fears are usually associated with expectations of discomfort or changes for the worse. Therefore, we cannot state that 
the result will be similar when other changes are introduced that may entail negative consequences for staff.

\section{References}

1. National Project - Labor Productivity and Employment Support (Government of the Russian Federation, 2019)

2. M. Hammer, J. Champy, Reengineering the Corporation (Harper Business, Australia, 2006)

3. M. Smyth, Performance Improvement 41(1), 26-33 (2002)

4. D. Bouckenooghe, The Journal of Applied Behavioral Science 46(4), 500-531 (2010)

5. J. Prochaska, C. DiClemente, J. Norcross, American Psychologist 47(9), 11021114 (1992)

6. I. Ajzen, Organizational Behavior and Human Decision Processes 50(2), 179-211 (1991)

7. V. Yadov, Self-regulation and prediction of social personality behavior: a dispositional concept (Moscow, 2013)

8. E. Naumtseva, Psychological readiness for organizational changes: approaches, concepts, methods, organizational psychology 2(6), 55-74 (2016)

9. D. Holt, A. Armenakis, H. Field, S. Harris, Journal of Applied Behavioral Science 42(3), 232-255 (2007)

10. R. Batchelor, Managing Change Saboteurs (or Destructors) (2011) https:/www.capillaryconsulting.com/managing-change-saboteurs-destructors/

11. Diagnostics of the company's readiness for targeted organizational transformation (OD) (Arbor Consulting Group) http://arborcg.org/product/od.

12. S. Cummings, T. Bridgman, K. Brown, Human Relations 69(1), 33-60 (2016)

13. K. Kane, Why companies need skeptics, https://www.kornferry.com/insights/articles/why-companies-need-skeptics. 